\title{
Cap And Trade Allowance Accounting: A Divergence Between Theory And Practice
}

Joseph M. Ragan, (E-mail: jragan@sju.edu), Saint Joseph's University A. J. Stagliano, (E-mail: astaglia@sju.edu), Saint Joseph's University

\begin{abstract}
This study concerns one of the most significant and glaring divergences between theory and practice that has emerged since the accounting discipline's conceptual framework was developed in the late 1970s. Through an extensive empirical examination of extant practices with respect to cap and trade allowances allotted to U.S. electric utilities under the Clean Air Act Amendments of 1990, this research demonstrates a surprising - and possibly unsupportable - divergence between expected and actual practice. The results of this research show that practice and theory diverge in a substantial and negative way. EPA-issued emissions allowances meet the accepted definition of an economic resource that will provide a future benefit, i.e., an asset. Yet, examination of five years' of public financial disclosures for the entities affected by the CAAA shows scant recognition for the acquisition, disposition, or year-end existence of these tradable emissions permits. Financial statement users and other stakeholders of the affected entities may be seriously misled by the failure to recognize the allowances. This divergence between theory and practice does not appear to be justifiable.
\end{abstract}

\section{INTRODUCTION}

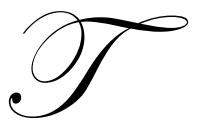

his is an exploratory study regarding accounting for cap and trade allowances - the contemporary best-practices method for encouraging private-sector environmental stewardship. The ultimate goal of this research, of which this paper reports a first step, is development of a conceptually justifiable and correct model for dealing with the acquisition, use, and disposition of pollution/effluent allowances that are part of governmental programs designed to curb environmentally destructive outputs from industrial production activities. This paper reports on an empirical review of the current state of accounting and disclosure in a specific portion of the U.S. electric utility sector.

The paper is arranged as follows. First, the general background on emissions-trading allowance programs is given. Next, the specific case of cap and trade allowances created by the Clean Air Act Amendments of 1990 (CAAA) is described. To set the stage for the empirical study, a very detailed explanation, supported by a full data set, of the CAAA-impacted segment of the U.S. electric utilities industry is given. A discussion of the method of study and residual population of entities from which data were developed follows. The empirical results are given as a prelude to provision of the conclusion, limitations, and future study questions.

\section{BACKGROUND: EMISSIONS-TRADING PROGRAMS}

Scientists have known for more than a century that rising atmospheric concentrations of negative outputs from industrial production affect climate, health of plants and animals (men/women included), and the overall quality of life. Nevertheless, agreement on how best to reduce these unwanted externalities has been slow in coming. A large part of the difficulty in this pollution-abatement process has to do with the enormous benefits derived from the same industrial processes that create the unwelcome by-products. Furthermore, there has not been - until quite recently - an acceptable means of dealing with the costs associated with reducing either the quantity or toxicity of emissions. 
The concept of trading in pollution rights (what we call emission or cap and trade allowances in this study) first appeared in the academic literature during the late 1960s (Anderson and Lohof 1997 and Dinan and Rogers 2000). The traditional approach, which this newer concept aims at supplanting, has often been termed "commandand-control." Fundamentally, the historic method sought to reduce harmful pollutants by mandate - basically a "thou shall not" legislated ban on certain kinds and/or levels of activity. Trading programs, on the other hand, use an economic-incentive solution to the problem of environmentally degrading industrial activities that are conducted to produce valuable goods and services of high demand. The rationale for moving away from command-and-control programs really is two-fold: (1) since negative externalities cannot be wholly prevented, curtailing/containing the environmental damage is an acceptable second-best solution; (2) market-based resolutions are feasible and, from an economic efficiency perspective, are superior to government fiat.

Over the years, emission allowances have been used to achieve a variety of environmental objectives in the United States. For example, the federal government, in cooperation with the states, has successfully used trading programs to gradually lower lead content in gasoline, phase out the use of ozone-depleting chemicals, reduce acid rain producing sulfur dioxide and smog-creating nitrogen oxides, and curtail uncontrolled dispersion of mercury. The European Union has had a carbon-emission trading mechanism in place for a few years, and there are current international negotiations on-going to extend this market in carbon dioxide permits to all the free-economy developed countries in the world.

The most significant commonality among all emissions trading programs is the setting of a cap on allowable effluent output as the goal. Movement toward that objective occurs because the pollution creators are given an economic incentive to reduce the negative externality. Under a typical trading program, the government sets a limit on the total permissible emission level. This might be done at the level of a production facility, over some specified geographic area, or for an entire country. Then, all the existing entities emitting the proscribed pollutant are granted permits - in aggregate, at the level of the emissions goal-for future discharges based on a scheme grounded in historic output measures. ${ }^{1}$ These allowances can be used to offset emissions (i.e., legitimate the actual pollution activity), sold to others, or "banked" for future use/sale.

\section{BACKGROUND: THE CLEAN AIR ACT CAP-AND-TRADE PROGRAM}

This exploratory research project focuses on a very specific cap-and-trade allowance program. This is done with the intent of assuring that the boundaries for examination - both in time of study and population of impacted players - are well defined so that the outcome of the research is amenable to clear and unambiguous interpretation.

Title IV of the Clean Air Act Amendments of 1990 actually was enacted as a remedy for the extraordinary omission from prior environmental protection legislation on the problem of acid rain (Freedman and Jaggi, 1993, p. 5). It specifically named 110 fossil-fuel-burning electric utility plants that were required to deal with their high rate of sulfur dioxide $\left(\mathrm{SO}_{2}\right)$ emissions in a two-phase approach. Each of these plants received an annual allocation of allowances that permitted sulfur dioxide emission of 80 percent of the firm's historical average from the 1985-87 period. ${ }^{2}$ This is the "cap," target, or goal of the pollution abatement legislation. It was expected that economically rational managements would choose the least-cost method to reduce emissions so as to comply with the law. This is the espoused purpose of permit trading programs: allow the efficiency of the marketplace to supplant mandated controls that previously had been used unsuccessfully.

Based on disclosures made during 1989 and 1990 by some of the companies impacted by the CAAA, significant expenditures having material negative effects on stakeholders were expected (Freedman, Jaggi, and Stagliano 2004). Phase 1 started in 1995, and although some firms incurred major capital expenditures by installing scrubbers or reconfiguring generators to handle a changed fuel mix, the majority either utilized low-sulfur coal or

\footnotetext{
${ }^{1}$ This method of distributing allowances based on historical data is called "grandfathering." Another method, not as common in usage quite yet, is termed "output-based allocation" and applies a variable-over-time permit distribution mechanism, the basis for which is recent past-period performance. The newly (2003) implemented EPA nitrogen oxides curtailment program is being put into effect in some states with this alternative distribution technique. In this regard, see Beamon, Leckey, and Martin (2002).

${ }^{2}$ See Dinan (2003) for an extended discussion of permit allocations and distribution techniques.
} 
purchased additional emission allowances to deal with the sulfur dioxide by-product of electric generation. In hindsight, it appears that most firms did choose the least costly way of reducing emissions.

Phase 2 began in 2000. Emissions levels were specifically delineated in the Act, and firms were awarewhen the law was enacted in 1990 - of the emissions standard they would be required to achieve under Phase 2. Part of the Phase 1 strategy for compliance would have been to prepare for Phase 2. Some firms did make appropriate preparations. A number of companies installed scrubbers and/or began to burn low-sulfur coal; these actions permitted them to bank their allowances in Phase 1 for future use. By the beginning of Phase 2, some firms had been able to reduce their emissions below the Phase 2 standard. A few firms purchased additional allowances on the market for current and future use.

For the analysis that will be developed below, it is essential to recognize that the $\mathrm{SO}_{2}$ acid rain program contained in Title IV of the CAAA is focused on coal-fired electric generating stations. Financial accounting for the cap and trade program, though, occurs at the level of the facility-owning entity. Therefore, the data provided below have been restructured so as to aggregate plant-level information and attribute that summary data to the corporate owner.

At the start of Phase 2, of the 43 entities that owned the 107 impacted power plants that were still operating then, 24 had an average pounds of $\mathrm{SO}_{2}$ per million BTUs generated ( $\mathrm{lbs} / \mathrm{mmBTU}$ ) greater than the 1.2 standard that was required under CAAA by the end of the year. ${ }^{3}$ As a consequence, these firms needed to find alternatives to cover the shortfall (i.e., their excess emissions). In Table 1 below, complete data on the firms, plants, 1999 sulfur dioxide emissions, and allowances banked/used for 2000 are provided.

The assumption is made in calculating the allowance shortfalls shown in Table 1 that these plants will emit the same amount of sulfur dioxide in 2000 as they did in 1999. If the firms that will be short of allowances did not wish to purchase them during 2000 (the allowance market price at the start of 2000 was only $\$ 135 /$ ton), then they needed to reduce their emissions. Of course, there were a number of routes available for emissions reduction, some with inherently higher costs than others. Furthermore, a number of firms that had banked allowances in Phase 1 presumably would consume many of them to meet the year 2000 emission requirements. These firms also would need a plan to deal with a potential allowance shortfall in the years beginning after 2000 .

Many firms (see Tables below) had excess allowances and would continue to generate net bankable (or, unused) allowances in the future. Although all firms with excess allowances in any given year hold assets and should record them as valuable ownership rights (see Grinnell and Hunt 2002), assets with no foreseeable use are investments subject to a market-based fluctuation in value. There is an expectation that they would be accounted for as such and disclosed in the financial statements provided to stakeholders and the SEC. We will see, after review of data, that this expectation has not been actualized.

Tables 1-3 provides the breakdown of firms by their allowance situation. These data are given to demonstrate that there are clear needs regarding accounting and disclosure for acquisition, use, and holding of tradable emission permits by these entities. These are not aberrational, special, or isolated examples. CAAA created a genuine need for dealing with the receipt and use of the intangible cap and trade allowance. The existence of the holding is undeniable; an unfettered market for value measurement was available; each holder's action (i.e., use, sell, or hold) with respect to the emission permits received from the U.S. Environmental Protection Agency (EPA) was not subject to contingency or speculation. ${ }^{4}$

\footnotetext{
${ }^{3}$ Although the allocation of allowances is based on tons of sulfur dioxide emissions, with each allowance permitting the plant to emit one ton of $\mathrm{SO}_{2}$, the legislative intent of Phase 2 is achievement of an average emissions level of $1.2 \mathrm{lbs} / \mathrm{mmBTU}$.

${ }^{4}$ Regarding the potential application of contingent-event accounting in this area, see SFAS No. 5 (FASB 1975).
} 
Table 1

Panel A

Firms Facing the Greatest Allowance Shortage in 2000

\begin{tabular}{ccc} 
Company & $\begin{array}{c}\text { Potential } \\
\text { Shortage }\end{array}$ & $\begin{array}{c}\text { Market Value } 1 / 1 / 00 \\
\text { (\$millions) }\end{array}$ \\
Dynergy & & \\
DQE & 221,881 & 29.954 \\
Allegheny Energy & 119,696 & 16.159 \\
Ohio Valley & 115,134 & 15.543 \\
TECO & 44,340 & 5.986 \\
Ipalco & 34,484 & 4.655 \\
First Energy & 34,056 & 4.598 \\
NRG & 30,925 & 4.175 \\
Northeast Utilities & 22,311 & 3.012 \\
\hline
\end{tabular}

Firms in the most drastic negative situation in terms of a potential deficiency in allowances are included in Table 1. In the year 2000, these companies had two choices in dealing with their sulfur dioxide emissions: either reduce emissions or purchase allowances. In Table 1, the cost of purchasing allowances that was known at the time (March 2000) the financial statements were issued is provided.

Table 2

Panel B

Firms Potentially Depleting Allowances Shortly After 12/31/00

\begin{tabular}{ccccc}
\hline & \multicolumn{2}{c}{ Est. 2000 } & Allowances in 2000 \\
Emissions & $\underline{\text { Current }}$ & $\underline{\text { Banked }}$ & $\underline{\text { Residual }}$ \\
AEP & 579,655 & 312,567 & 356,519 & 89,431 \\
Ameren & 160,658 & 117,990 & 48,799 & 6,131 \\
Cinergy & 423,749 & 185,567 & 235,721 & $(2,461)$ \\
Conectiv & 15,302 & 11,162 & 7,789 & 24,649 \\
Empire District & 34,229 & 15,766 & 43,038 & $(931)$ \\
Hoosier Electric & 17,180 & 7,253 & 8,996 & 9,442 \\
Sithe Energy & 78,105 & 28,040 & 59,507 & \\
\hline
\end{tabular}

In Table 2, firms that have a longer-term problem in dealing with emissions are listed. These firms can still emit as much sulfur dioxide in 2000 as they did in 1999 and be fully covered for these emissions. However, in the years beginning with 2001 they would need to either reduce emissions or buy allowances. 
Table 3

Panel C

Firms with Surplus (Marketable) Allowances at 12/31/00

\begin{tabular}{ccc}
\hline Company & $\begin{array}{c}\text { Surplus } \\
\text { Allowances }\end{array}$ & $\begin{array}{c}\text { Market Value } \\
\text { (\$millions) }\end{array}$ \\
Keyspan & & 54.283 \\
Electric Energy & 402,099 & 29.198 \\
Alliant & 216,285 & 22.603 \\
Nisource & 167,433 & 26.999 \\
Vectran/Sigeco & 199,991 & 14.485 \\
Associated Elec. & 107,297 & 11.201 \\
East KY Coop & 82,971 & 8.102 \\
PA P\&L & 60,018 & 5.471 \\
Wisconsin Energy & 40,523 & 3.675 \\
CMS & 27,223 & 3.184 \\
Springfield Muni & 23,585 & 2.715 \\
Owensboro Muni & 20,112 & 2.510 \\
Henderson Muni & 18,592 & 2.259 \\
Kansas City P\&L & 16,735 & 0.959 \\
Wisconsin PSC & 7,107 & 0.608 \\
\hline
\end{tabular}

Table 3 shows the firms that do not need their banked allowances. Plants owned by these firms are collectively emitting less sulfur dioxide than the annual allowance allocation provided by the EPA. In effect, these operators have met the cap goal of emissions reduction to 80 percent of the pre-CAAA level. Therefore, every year these companies will have surplus allowances to bank or trade. Some states require that if these allowances are sold the proceeds must be used to reduce the price of generated power (Wisconsin Public Service Co. 2000), but most jurisdictions have no such restriction. ${ }^{5}$ Whatever the case may be, these firms are, effectively, creating an investment asset each year.

From the perspective of either an investor or creditor, how these firms choose to deal with Phase 2 is of significant interest. Many of the electric utility firms directly impacted by Phase 2 faced short- and long-term decisions that had implications for future economic performance. Disclosing these plans would help investors and creditors better assess risk and aid in projecting future returns. Accounting for acquisition, application, and holding of $\mathrm{SO}_{2}$ emission permits would seem to be called for under any interpretation of the existing conceptual accounting framework. So, also, it would seem that disclosure in this area would be essential for a "fair presentation" of financial results that management must provide for publicly traded companies and that independent accountants must attest to as part of their assurance function.

In addition to investors and creditors, a number of other stakeholders have an interest in the electric utilities' plans to deal with CAAA Phase 2. Employees, for example, would like to know if the plans include shutting down plants, or reduction/increase of electricity generation at other facilities. Given the nature of the electric utility industry, with generating plants being traded almost as if in a "fire sale," it is especially important to know how Phase 2 might contribute to the stability and salability of generating facilities.

\footnotetext{
${ }^{5}$ At least one company (Pennsylvania Power \& Light during 2004) instituted a policy of donating certain "excess" cap and trade allowances under CAAA to designated nonprofit organizations. Seemingly, recognition and measurement to carry out such a program was not deemed problematic by the company.
} 
Suppliers also may be impacted by the Phase 2 plan. If a company chooses to reduce emissions by changing the type or mix of fuel burned or elects to use a scrubber with high sulfur content coal, for example, then that impact would be felt by the supplier. Customers (rate-payers) are affected because even in the period of continuing wide-scale deregulation (2000 to 2003) of this industry, costs still were being passed along to them. If the company installs scrubbers or buys allowances, rate-payers will be the ones who must cover the costs. However, if the company sells excess allowances, the rate-payers may or not benefit from this sale. Financial statement disclosures can help inform decision makers in this area.

People affected by sulfur dioxide emissions - whether in the immediate community or downwind of the pollution source-are impacted by how the company chooses to deal with Phase 2. If the company decides to comply by purchasing allowances and not by reducing pollution, the emissions will contribute to dirtying the air, land, and water. A company might reduce emissions at certain plants and still emit a huge amount (in both absolute and relative terms) of sulfur dioxide. Communities downwind from these high-emission plants may be severely impacted, even though the company as a whole has reduced its pollution. Accounting data, if made available, will assist these stakeholders in understanding how CAAA compliance impacts them.

\section{CONDUCT OF THE EMPIRICAL STUDY}

Our interest here is in the method and level of disclosure that the companies which owned the impacted facilities exhibited in their financial statements during the complete CAAA Phase 2 period. We are not concerned in this study with measurement and/or valuation issues. While we did study seven years (1999, the last year in Phase 1 , through 2005, the year after the CAAA two-phase process was completed), only the complete results of the empirical examination for the Phase 2 period (i.e., 2000 to 2004) are described in this manuscript.

It will prove instructive at this point, we believe, to give a concrete example of where the accounting and disclosure difficulties lie, and why we propose that theory and practice diverged when cap and trade allowances emerged as the preferred government-sponsored means for environmental protection in the case of acid rain. In 1999, American Electric Power, anticipating its future need to comply with Phase 2 standards, spent about $\$ 37$ million to purchase sulfur dioxide emissions allowances on the spot and futures markets (EPA 2004). This information - available, with an 18-month time lag, from EPA public-domain data sources - was not disclosed in the company's annual report to shareholders or in its Form 10-K annual report to the U.S. Securities and Exchange Commission (SEC). No information was included in these reports regarding how the firm planned to achieve the emission standards of Phase 2 either. Potomac Electric Power Company, on the other hand, disclosed in its 1999 Form 10-K that it planned to spend $\$ 5$ million to comply with Phase 2 and would sell its remaining electricgenerating plants (PEPCO 1999). ${ }^{6}$ Stakeholders and regulators might view these two "events" and wonder why there is no consistency in disclosure concerning the CAAA requirements. This is especially so given that the Act mandates specific remedies for non-compliance and is known to have given rise to significant capital expenditures.

The time period for our study is the inclusive years of CAAA Phase 2: 2000 through 2004. We select Phase 2 since we want to be certain to deal only with a time period in which the affected players will have had ample opportunity to "learn" what is required to account for the CAAA economic impacts. Further, we allow five full years after enactment for the standards setting bodies - the American Institute of CPAs, the Financial Accounting Standards Board, and the SEC - to deal with any actual or perceived difficulty on the accounting, auditing, measurement, disclosure, and display issues that arose as a consequence of this legislation's enactment and implementation.

We are quite fortunate in this study to have the complete population of impacted entities specified, so a robust analysis is possible that will not require inferential reasoning from a sample for its conclusions to have power. As in all empirical research, especially that which depends upon a retrospective collection of data, a number of factors intervened to preclude truly complete information acquisition in an absolute sense.

\footnotetext{
${ }^{6}$ Obviously, since we focus on Phase 2 in our work here, PEPCO does not appear in the previously described data tables since it was without actual generating capacity — the focus of CAAA— during the study time period.
} 
As was stated earlier, Phase 1 targeted 110 coal-fired power plants for reduction of sulfur dioxide emissions. These plants were among the ones that emitted the most sulfur dioxide (in both absolute and relative terms) in the country. Although Phase 2 included all fossil-fuel power plants above the 25 megawatt capacity level, most of the facilities were quite small and emitted little sulfur dioxide (Ellerman 2003). Of the 110 Phase 1 plants targeted, 107 were still operating in year 2000 when Phase 2 went into effect.

At the start of Phase 2, these 107 plants were owned by 43 different entities. Eleven of these entities, though, were energy cooperatives, closely-held corporations/partnerships, or municipalities for which full public financial disclosures generally are not available. We exclude from analysis the Tennessee Valley Authority, a U.S. government company/instrumentality that does make public financial disclosures, since it is not bound by the same conceptual accounting model as investor-owned, publicly held companies. Remaining, then, are 32 electric utility companies. Four of these did not survive as separately reporting entities throughout all of the Phase 2 period, and are excised from the study group, even though it can be said that nearly all, but not all, of their owned/operated CAAA-named generating stations are captured in the data from the companies remaining in our diminished population group. Finally, while we would expect that the study group should contain 140 observations (i.e., 28 companies over a 5-year period), usable and complete data sources could not be accessed in digital form for 15 of these potential points of review. We have no reason to believe, but cannot demonstrate, that the non-systematic loss of approximately 11 percent of the maximum potential observable population group will bias the results of our study or diminish the strength/veracity of our conclusions.

What CAA Phase 2 requires in terms of sulfur dioxide emissions is that electric power plants have enough allowances to cover all emissions each year into the foreseeable future. Each targeted fossil-fuel burning power plant was provided an annual allocation of emissions allowances to cover a fixed percentage of prior yearly sulfur dioxide emissions. In CAAA Phase 1, which covered the period 1995-99, the allocation was designed so that an overall emission level of $2.5 \mathrm{lbs} / \mathrm{mmBTU}$ would be achieved (EPA 2002). Phase 2 began in the year 2000 and the allocation was designed so that the overall emissions do not exceed $1.2 \mathrm{lbs} / \mathrm{mmBTU}$. Obviously, in Phase 2 the standard is set so that firms minimally achieving the Phase 1 requirement of $2.5 \mathrm{lbs} / \mathrm{mmBTU}$ would be required to further reduce sulfur dioxide emissions by 50 percent.

Before detailing the results of the study, it is useful to provide some additional conceptual support for the proposition that our expectations regarding disclosure of this environmental information are well grounded. Disclosure of information concerning how electric generating firms plan to deal with CAAA Phase 2 compliance is important to stakeholders of impacted firms. However, as the U.S. General Accounting Office (GAO) discovered in its recent study on environmental disclosures (GAO 2004), there is little guidance as to what must be disclosed. SFAS No. 5 requires that contingent liabilities be disclosed if they are reasonably probable, estimable, and material in amount. The SEC does not have a materiality constraint per se, but it does allude to the need for disclosure if a "reasonable person" would need the information for an investment decision.

Why should we expect that electric utility firms would provide information about their plans for compliance with Phase 2? Why do we believe that cap and trade allowances that were allocated through the impacted facilities to the companies studied will appear in their financial disclosures?

In the accounting literature, several alternative theories have been posited as explanations for disclosure concerning firms' environmental stewardship. Patten (1991), Savage et al. (2000), and Lindblom (1994) all believe that one reason firms make environmental (or social) disclosures is for legitimation purposes. In terms of environmental stewardship, firms try to provide congruence between society's expectation of environmental performance and the firm's externally perceived performance.

A firm in an environmentally sensitive industry-like electric power generation - that ignores the public's demand for a certain level of environmental stewardship is put at risk as being labeled a "bad corporate citizen." That characterization could have negative economic consequences for a variety of stakeholders, not the least of which includes the current group of equity holders. By managing environmental information so that the firm appears to be doing well in meeting society's environmental goals, the firm is seen as being legitimate. Thus, by 
disclosing environmental information to meet society's expectations the firm can avoid some negative consequences

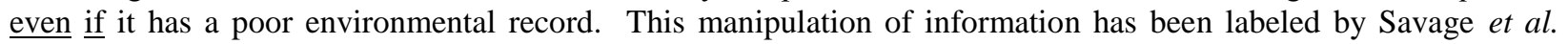
(2000) as legitimation.

Stakeholder theory (Ullmann 1985, Roberts 1992, and Clarkson 1995) posits that disclosure is a function of stakeholder demand for environmental and social information. Management responds to stakeholders' public pressure through the voluntary disclosure of the information demanded. Although it is similar to legitimacy theory in that there is a reaction to public pressure, each stakeholder constituency seeks information that is tailored to its needs. Furthermore, stakeholder theory does not assume that the information disclosed will necessarily be selfserving or distorted.

Electric utility companies that have not yet met the Phase 2 standard, that need to purchase allowances, and/or are emitting relatively more sulfur dioxide than permitted by CAA standards will need to incur additional costs to solve these problems. From a social standpoint, these firms are all in jeopardy of being perceived as poor corporate citizens. From a legitimacy theory framework, companies that are perceived to have environmental problems and do not disclose their plans to deal with these problems would be looked upon unfavorably by society. From a stakeholder theory perspective, the various concerned groups that were previously discussed would have an interest in knowing about firms' environmental stewardship. Investors and creditors, for example, would be interested to know what additional costs will be incurred to meet the Phase 2 requirements and whether these costs can be passed along to the electric utility's customers.

Above all, there is a reasonable expectation that each corporate enterprise will appropriately account for the resources that have been entrusted to it through publicly supplied capital. Notwithstanding the controversy that might arise in valuation ${ }^{7}$ of EPA-granted cap and trade allowances (see, for example, Hopp 1994 and Wambsganss and Sanford 1996) at the time of their receipt, there can be little doubt that market-based purchase and sale transactions merit contemporaneous recognition for which measurement is not in doubt.

Further, the year-end reckoning of each entity's ownership of valuable resources that are expected to have value in the future - the classical definition of asset accounting - cannot but fail to include unused cap and trade allowances, whether they are considered "inventory," investment assets held for future use, or intangible rights that are tradable like any other marketable security ${ }^{8}$. Finally, to the extent that a utility company has a known expected shortfall of cap and trade allowance position in its next fiscal year (see, for example, Panel A of Table 2 referred to previously), there is every reason to believe that disclosure - measured and "booked" on the balance sheet, or shown in a financial statement footnote-would occur as part of any fair presentation of the financial health of the enterprise.

\section{STUDY RESULTS}

Information on company disclosures concerning cap and trade allowances was searched for in Form 10-Ks. Company annual reports to stockholders, environmental reports, sustainability statements, corporate responsibility "score cards," and all other communications were disregarded. The reason for this exclusive focus on the SEC filing is simple and straightforward: Form 10-K contains the legally mandated financial disclosures of the companies studied that must be reported in compliance with generally accepted accounting principles and contains an assurance that attestation of fair presentation by independent accountants has occurred within the context of generally accepted auditing standards. In this paper, we do not deal with voluntary disclosures of environmental and social accounting information. This electronic search was conducted by two separate reviewers, with the outcome assessed by a third reader.

\footnotetext{
${ }^{7} \mathrm{SO}_{2}$ allowances are traded regularly on the Chicago Board of Trade (CBT). The EPA publishes all CBT transactions related to emission allowances, showing units and prices. Since these pollution permits are treated as "restricted security instruments," the EPA also compiles/publishes information on every private trade of allowances that does not occur on the CBT.

${ }^{8}$ An obvious complication in accounting for cap and trade allowances, since they are deemed to be marketable intangible rights, is the assessment required in the FASB's mark-to-market rules for balance sheet classification and valuation purposes. On this issue, see SFAS No. 115 (FASB 1993).
} 
There were 125 statements in the final review. Table 4 shows the summary results of our observations.

Table 4

Disclosure Observations

$\begin{array}{lll}\text { No Disclosure } & 61 & 49 \% \\ \text { Qualitative Disclosure } & 47 & 37 \% \\ \text { Quantitative Disclosure } & 17 & 14 \%\end{array}$

Turning, first, to the large number and percent of observed failures to account for cap and trade allowances in any way, we add the further result that 25 percent of these entities exhibited this pattern of non-accounting throughout the entire 5-year study period.

Next, while we have not conducted a detailed content analysis of the non-quantitative disclosures that were found, we might further categorize these financial statement commentaries as either (1) general discussions about CAAA and $\mathrm{SO}_{2}$ allowances (mixed, at times, with discussion about the $\mathrm{NO}_{\mathrm{X}}$ control program), or (2) more specific reporting about the means whereby the company has chosen to deal with cap and trade permits in its operations so as to comply with environmental laws. Into this first, less specific, category we would include 9 of these 47 observations; in the other part of this dichotomy would fall the other 38 disclosures. It is appropriate to state that these disclosures were gleaned from the "Legal Matters" section of the Form 10-K, the "Management Discussion and Analysis" item, and-less often - from financial statement footnotes. In any case, we have not performed a content analysis of the disclosures but remark that just over a third of our observation points are characterized by this literal form of disclosure related to an obviously quantifiable financial statement item.

Finally, it will be useful to describe in more detail the quantitative disclosure methods discovered. To begin with, there are only 12 companies in this group. Thus, in our attempt to find reasonable compliance with the accepted accounting and financial-markets definition of an asset, less than 45 percent of the firms studied - all large, richly capitalized and mature companies - deemed it appropriate to place a dollar valuation on CAAA cap and trade allowances that they received, applied, bought, sold, or held at year end.

With respect to categorizing the "area" of financial reporting for the 17 disclosures we found among all the companies, we report that one was found in the statement of cash flows, seven were operating statement related, and the remaining nine were balance sheet disclosures. The single cash flow statement reporter classified transactions related to emission allowances as an investing activity. Six companies reported dollar amounts of either gross sales or net gains (as expected, no company incurred a loss on trading emission permits) from disposing of allowances; one firm placed a dollar amount on the expenses related to using allowances to permit its emission of $\mathrm{SO}_{2}$. $\mathrm{Balance}$ sheet reporting came in four varieties: one firm showed the value of year-end allowances as a tradable investment asset, four accounted for the permits as an inventory item, one utility categorized its allowances as a long-lived intangible, and three quantitative disclosers reported dollar amounts for cap and trade allowances in the liability section. This extreme variety of reporting is, to our way of thinking, a somewhat astounding outcome of our observations! 


\section{CONCLUSIONS, LIMITATIONS, AND FURTHER STUDY}

As we stated at the outset, this is an exploratory study that, while setting forth the full data collected for future use, intends a narrow focus. The issue concerned is accounting for, and disclosure of, cap and trade emission allowances by electric utilities as they dealt with compliance under Phase 2 of the CAAA. To meet the requirements of Phase 2, firms had to reduce emissions or acquire enough allowances to cover their shortfall. At the highest level of concern, disclosing their current sulfur dioxide emissions, how they plan to meet the Phase 2 standards, and the future cost of implementing their plans would enable stakeholders to properly assess the implications of Phase 2 on the firm.

For this study, though, our expectations were focused on firms with current or future surplus allowances disclosing how they planned to dispose of the allowances, a method for their valuation, and the carrying value of the asset. We anticipated seeing quantitative disclosure of the costs of using and purchasing allowances. The conceptual accounting framework led us to look for gains and/or losses being recorded for sales of CAAA permits by the large number of firms with excess allowances under Phase 2 .

It is not unreasonable to conclude that these rather fundamental expectations regarding cap and trade allowance accounting, disclosure, and financial statement display went largely unfulfilled. We are led to suggest that the theoretical or conceptual treatment for this relatively new type of readily marketable intangible right was not translated into practice.

The study conducted is not without limitations. It is possible, though not highly probable, that we have erred in our interpretation of the accounting model and its "definition" of items that are assets. Our choice of data source - annual reports to the SEC on Form 10-K - might have been too narrow to capture the disclosures predicted to exist. The statement review technique, using only an electronic filter search, might have failed to adequately uncover all of the disclosures that did in fact occur. Finally, the period for analysis might have been too short, the range of companies too limited, the focus on CAAA cap and trade allowances too narrow, or the amount of inaccessible (i.e., missing) data too great for us to have appropriately studied this subject in a way that lends substantial credence to the outcomes we have reported here.

Each of these limitations will require review to determine whether future studies of this nature will bring the same result. For example, two additional years of data beyond the Phase 2 period now are available. Possibly, inclusion of these data will generate results more in line with expectations. On the other hand, it is possible that the conceptual accounting model simply is inadequate to deal with the matter of cap and trade permits. The observed failure of practice to comport with theory may signal that this is the case. The enormous diversity in practice that is evident from the results of this study might be an indicator that a remedy for such an inadequacy of the accounting model will not easily be put right.

What is clear from this study is that firms that face nearly the same externally imposed operating challenges differentially disclose their status to stakeholders. Some of the disclosure can be linked to the environmental situation in which the firm finds itself with respect to Phase 2. In that sense, disclosure is a function of pollution performance and not of legitimation. However, with a tightly defined and small study group, an industry that is still regulated in many ways, and a unique set of stakeholders, it may not be not possible to generalize from these findings and extrapolate our results to other time periods, companies, or different allowance trading programs.

Still, disclosures by companies impacted by Phase 2, like those concerned with the impacts of other environmental legislation, are relatively poor. Despite the GAO's protestations to the contrary, mandated disclosures that companies seem to perceive as voluntary, are insufficient to inform stakeholders. Unless the SEC strengthens oversight or the various standard setters are more specific about the correct accounting treatment in this area, the existing observed circumstances are not likely to change. 


\section{REFERENCES}

1. Anderson, Robert C. and Andrew Q. Lohof. 1997. The United States' experience with economic incentives in environmental pollution control policy. Washington, DC: Environmental Law Institute.

2. Beamon, Alan, Tom Leckey, and Laura Martin. 2002. Power Plant Emission Reductions Using a Generation Performance Standard. Washington, DC: U.S. Department of Energy, Energy Information Administration.

3. Clarkson, Max. 1995. A stakeholder framework for analyzing and evaluating corporate social performance. Academy of Management Review. 20, 1: 92-117.

4. Dinan, Terry. 2003. Shifting the Burden of a Carbon Cap-and-Trade Program. Washington, DC: Congressional Budget Office.

5. Dinan, Terry and Diane Lim Rogers. 2000. Who Gains and Who Pays Under Carbon-Allowance Trading? The Distributional Effects pf Alternative Policy Designs. Washington, DC: Congressional Budget Office.

6. Ellerman, A. D. 2003. Lessons from phase 2 compliance with the U.S. acid rain program. MIT Center for Energy and Environmental Policy Research. Working paper.

7. EPA. 2004. Emissions tracking site for acid rain. ETS/CEMS. Website: http://www.epa.gov/ardpublic/edata.html.

8. EPA. 2003. 2002 Progress Report. EPA Acid Rain Program. Clean Air Markets Program.

9. EPA. 2002. 2001 Progress Report. EPA Acid Rain Program. Clean Air Markets Program.

10. Financial Accounting Standards Board. 1975. Statement of Financial Accounting Standards No. 5: Accounting for Contingencies. Stamford, CT.

11. Financial Accounting Standards Board. 1993. Statement of Financial Accounting Standards No. 115: Accounting for Certain Investments in Debt and Equity Securities. Stamford, CT.

12. Freedman, Martin and Bikki Jaggi. 1993. Air and Water Pollution Regulation: Accomplishments and Economic Consequences. Westport, CT: Quorum Books.

13. Freedman, Martin, Bikki Jaggi and A. J. Stagliano. 2004. Impact of the Clean Air Act of 1990 on pollution disclosures by electric utilities. Advances in Environmental Accounting and Management. 2: 59100.

14. GAO. 2004. Environmental disclosure: SEC should explore ways to improve tracking and transparency of information. Washington, DC: GAO.

15. Grinnell, D. J. and H. G. Hunt, III. 2002. Gifted pollution allowances: Recognizing a liability to society. Critical Perspectives on Accounting. 13, 2: 211-30.

16. Hopp, Rachel M. 1994. Accounting for emissions trading programs. The Journal of Corporate Accounting and Finance. 5, 4: 487.

17. Lindblom, C. K. 1994. The implication of organizational legitimacy for corporate social performance and disclosure. Unpublished manuscript presented at the 1994 Critical Perspectives on Accounting Conference.

18. Patten, Dennis. 1991. Exposure, legitimacy and social disclosure. Journal of Accounting and Public Policy. 10 (Winter): 297-308.

19. Pennsylvania Power \& Light Company. 2003. PP\&L Form 10-K report.

20. PEPCO. 1999. Potomac Electric Power Form 10-K report.

21. Roberts, R. W. 1992. Determinants of corporate social responsibility disclosure: An application of stakeholder theory. Accounting, Organization and Society. 17: 595-612.

22. Savage, Arline, A. J. Cataldo, and Jeff Rowlands. 2000. A multi-case investigation of environmental legitimation in annual reports. Advances in Environmental Accounting and Management. 1: 45-82.

23. Ullmann, Arieh. 1985. Data in search of a theory: A critical examination of the relationships among social performance, social disclosure and economic performance of US firms. Academy of Management Review. 10, 3: 540-57.

24. Wambsganss, Jacob R. and Brent Sanford. 1996. The problem with reporting pollution allowances. Critical Perspectives on Accounting. 7, 6: 643-52.

25. Wisconsin Public Service Company. 2000. Wisconsin Public Service Company Form 10-K report. 
Journal of Business \& Economics Research - November 2007

Volume 5, Number 11

NOTES 